\title{
MULTI-OBJECTIVE OPTIMIZATION OF REINFORCED CONCRETE FRAMES USING NSGA-II ALGORITHM
}

\author{
Mehdi BABAEI, Masoud MOLLAYI \\ Department of Civil Engineering, Faculty of Engineering, University of Zanjan, Zanjan, Iran
}

Received 25 April 2016; accepted 16 October 2016

\begin{abstract}
In recent decades, the use of genetic algorithm (GA) for optimization of structures has been highly attractive in the study of concrete and steel structures aiming at weight optimization. However, it has been challenging for multi-objective optimization to determine the trade-off between objective functions and to obtain the Pareto-front for reinforced concrete (RC) and steel structures. Among different methods introduced for multi-objective optimization based on genetic algorithms, Non-Dominated Sorting Genetic Algorithm II (NSGA II) is one of the most popular algorithms. In this paper, multi-objective optimization of RC moment resisting frame structures considering two objective functions of cost and displacement are introduced and examined. Three design models are optimized using the NSGA-II algorithm. Evaluation of optimal solutions and the algorithm process are discussed in details. Sections of beams and columns are considered as design variables and the specifications of the American Concrete Institute (ACI) are employed as the design constraints. Pareto-fronts for the objective space have been obtained for RC frame models of four, eight and twelve floors. The results indicate smooth Pareto-fronts and prove the speed and accuracy of the method.
\end{abstract}

Keywords: NSGA-II, multi-objective optimization, moment resisting frame, reinforced concrete, weight, displacement, Pareto front.

\section{Introduction}

Considering the fact that reinforced concrete (RC) structures compared to steel structures have more variety in materials, hence optimization of RC structures are more complex than steel structures. Among the variables included in the optimization of RC structures are: compressive strength of concrete, steel yield stress, size of cross sections, and percentage of reinforcements, shape and topology of the structure. To calculate an RC building structural cost, three parameters including the required volume of concrete, weight of reinforcement steel, and formwork are important. It should be noted that labor costs should also be added to the above costs, although one can include labor costs in the cost of formwork, as it has been assumed in this article.
Optimization using genetic algorithms has been welcomed in recent decades by many researchers. The research conducted by Hoit et al. (1991) focused on minimizing the weight of the structure using Lagrangian method and nonlinear techniques. In 1994, Adamu et al. (1994) published an article about optimization of the cost of RC beams. In 1997, Baling and Yao (1997) published a paper on the three-dimensional optimization of RC frames using multi-layer methods. In 2003, the article of Camp et al. (2003) was published about optimization of moment resisting frames using genetic algorithms.

Cellular automata method was applied to optimize the continuum structures (Sanaei, Babaei 2012), reporting interesting results. Analysis and optimization of elastic-plastic framing structures was investi- 
gated under complex constraints (Gervytè, Jarmolajeva 2013). The impact of ductility levels on the cost of RC moment resisting frames for buildings with 5 to 15 floors was investigated (Babaei 2015b). Optimization of RC frames to determine the best topology and optimal arrangement of columns have been studied in structures ranging from 5 to 10 floors (Babaei 2015a). Similar studies were carried out to explore optimal topology for steel structures (Babaei, Jabbar 2016; Babaei, Omidi 2015).

On the other hand, it is inevitable to consider more than one objective function for engineering optimization problems. Therefore, multi-objective optimization has been introduced and applied in many fields of engineering practice (Deb 2001; Andersson 2001; Ghosh, Dehuri 2004; Carrillo, Taboada 2012). In recent years, many multi-objective optimization methods based on genetic algorithm have been presented, including weighted sum method (WSM) (Kim, De Weck 2005), vector evaluated genetic algorithm (VEGA) (Ghosh, Dehuri 2004), strength Pareto evolutionary algorithm (SPEA) (Sarker et al. 2002), Niched Pareto genetic algorithm (NPGA) (Horn et al. 1994), and non-dominated sorting genetic algorithm (NSGA) (Deb et al. 2000).

In recent years, the powerful algorithms of NSGA have been used for the optimization in various fields including RC structures. Some of these studies are: two-objective optimization of $\mathrm{CO}_{2}$ emissions and cost for composite building design using NSGA (Park et al. 2012), synthesis of truss structure designs by NSGA-II and Node Sort algorithm (Stanković et al. 2012), and cost and $\mathrm{CO}_{2}$ emission optimization of steel reinforced concrete columns in high-rise buildings (Park et al. 2013). A comparative study for two meta-heuristic algorithms and big bang-big crunch for optimal design of RC frames carried out and reported in the literature (Kaveh, Sabzi 2011, 2012).

The following section deals with the optimization process by introducing objective function, constraints, code specifications and design variables for RC moment resisting frames. Section 2 describes the NSGAII algorithm for optimal design. Section 3 includes test models to illustrate the capability of the algorithm. Significant conclusions are drawn at the end of the paper.

\section{Optimization process}

\subsection{Objective functions definition}

In this paper, two different objective functions are presented. The first objective function is the structural cost and the second criterion to be optimized is the maximum lateral displacement. For this purpose, the cost is calculated on the basis of three parameters: volume of the required concrete, weight of the required reinforcement, and the cost of formwork and labor. Both objective functions have to be minimized. Therefore, the first objective function for cost minimization is introduced as follows:

$$
F_{c}=f\left(P_{s}, P_{c}, P_{f}\right),
$$

where $F_{c}$ is the objective function to minimize construction cost, $P_{s}$ is the cost of the required reinforcement, $P_{c}$ is the cost of the required concrete and $P_{f}$ is the cost of formwork and labor.

Design variables are assumed to be the dimensions of cross sections and the cross sectional area of reinforcement bars. Standard problem formulation is as follows:

$$
\begin{gathered}
\text { Minimize } F_{1}=f\left(P_{s}, P_{c}, P_{f}\right) ; \\
F_{1}=\sum_{\text {element }} C_{s} L A_{s}+C_{c} L b h+C_{f} L p ;
\end{gathered}
$$

$$
\text { Minimize } F_{2}=\max (\text { roof displacement }),
$$

where, $C_{c}$ is the cost of concrete per unit volume, $C_{s}$ is the cost of reinforcement per unit volume, $C_{f}$ is the cost of formwork per unit area, $L$ is the cross section length, $A_{s}$ is the cross section area of reinforcement, $b$ is the cross sectional width of the beams or columns, $h$ is the cross sectional length of the beams or columns, and $p$ is the perimeter of the cross sections.

\subsection{Constraints and penalty functions definition}

Almost all engineering optimization problems include constraints, which have to be satisfied by each feasible design. In optimal design of RC moment resisting frames, there following constraints are applied.

The stress constraints are as:

$$
\left|\frac{\sigma_{i}}{\sigma_{i}^{a}}\right| \leq 1, \quad i=1 \text { to } n .
$$

In addition, the displacement constraints are:

$$
\delta_{i} \leq \delta_{\max }, \quad i=1 \text { to } m,
$$

where $\sigma_{i}$ and $\sigma_{i}^{a}$ are the existing and allowable bending stresses, respectively; $\delta_{i}$ and $\delta_{\max }$ are the story and allowable displacements, respectively. 
To satisfy all constraints in an optimization problem, one of the popular methods developed in the literature is to define penalty functions. On the other hand, from the construction point of view, columns of the lower levels must have larger dimensions than the columns located in the upper floors, as well as, the reinforcing bars and their number in the upper columns must be less than or equal to the lower columns. Other restrictions related to the design code requirements must also be satisfied. In the penalty approach, if a constraint is not satisfied, the objective (cost or displacement) functions are penalized. In this method, in addition to simplifying the objective function, restrictions will be applied in such a way that the cost of structures or their displacement is increased, so automatically a penalized design would have a little chance to be selected as an optimal solution. Many methods are developed in the literature to introduce penalty function. In this article, the penalty function is applied as follows:

$$
\begin{aligned}
& C_{i}=\alpha_{i} V_{i} ; \\
& \Phi=\sum_{i=1}^{n} C_{i} .
\end{aligned}
$$

In these equations $C_{i}$ is the penalty function for each of the constraints, $\alpha_{i}$ is penalty factor of each constraint, $V_{i}$ is the amount of each penalty, and $\varphi$ is the total penalty. Based to the problem, penalty coefficient values are obtained through trial and error, and are unique values for each of the structures (Carrillo, Taboada 2012).

\subsection{ACI Specifications}

In this study, the American Concrete Institute (ACI) Code restrictions for each of the elements and all the requirements for the number and location of reinforcing bars are applied and satisfied through designing the structural elements. Constraints are applied using a penalty function as introduced in the previous section. There are different methods for calculating penalties. Constraints need to be satisfied by two types of elements in a frame structure; columns and beams. In a column there is an interaction between axial load and bending moment and this interaction has to be considered to evaluate the strength of a column, instead of a separate design for axial force and bending moment. To apply penalties to a column, which is under axial load and bending moment, the following formula is used, using the description in Figure 1.

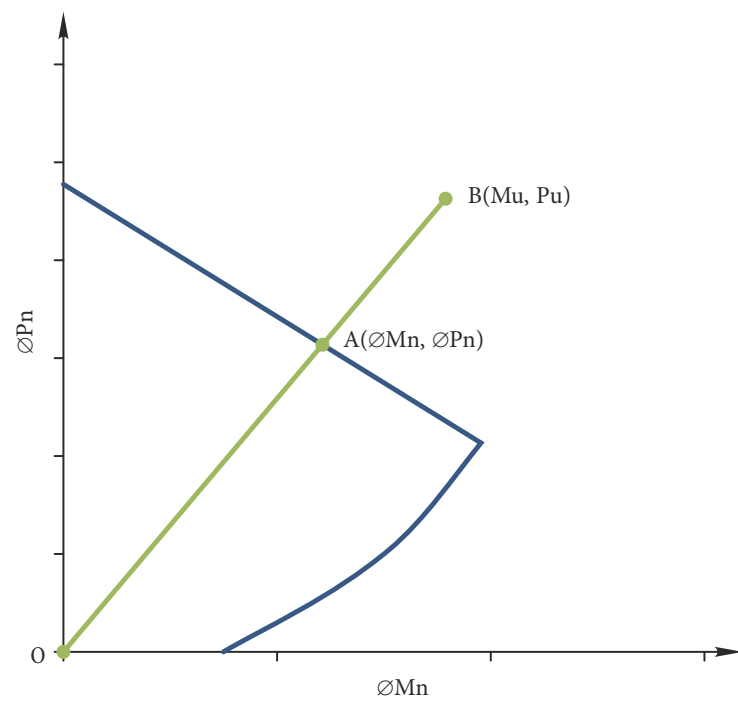

Fig. 1. Penalty calculation in columns

$$
\text { Column penalty }=\frac{B O-A O}{A O} .
$$

For beams, it is less complex to apply penalties than for columns. It needs only to calculate the ratio of the applying bending moment to the bending strength of the section. When this ratio is less or equal to 1 , then there is no need for penalty, otherwise the element must be penalized. Reinforcement ratio limits for columns and beams, distance between bars, and other code regulations are imposed to all structural models of this study.

\section{NSGA-II algorithm}

Inspired from the nature, GA is one of the meta-heuristic algorithms that have been welcomed by many researchers in recent decades. Genetic algorithms are used to solve single objective optimization problems while NSGAs are developed to solve multiobjective optimization problems. GA selects the most qualified chromosomes and sends them to the next generation. Through selection, crossover, and mutation operations, the algorithm finds the best solution. Non-dominated sorting algorithm II (NSGA-II) algorithm, suggested in 2000 by Deb and his colleagues (Deb et al. 2000), is an algorithm based on genetic algorithm (GA) for multi-objective optimization problems (Andersson 2001; Ghosh, Dehuri 2004; Deb et al. 2000; Deb 2001). Compared to the first version of the algorithm, the second version of the NSGA is faster. In both versions of the algorithm, all members of the population are compared to each other based on the 
objective functions. In NSGA-II congestion distance is used as an important parameter to improve the algorithm. This parameter provides an appropriate diversity for the members of the population.

\section{Test models and results}

In this paper, three different sample models were studied to evaluate the performance of the algorithm. The topologies of the models are similar to those studied in the previous works of the literature (Kaveh, Sabzi 2011, 2012). These models of three-span structures with four, eight and twelve floors are considered as representative structures for low, medium and high rise buildings. For all models a story height of $3.3 \mathrm{~m}$ and a span of $7.5 \mathrm{~m}$ are considered. Uniform live and dead loads are applied to beams and lateral loads are distributed between beam-column joints. According to the ACI regulations three load combinations are considered to design structural elements as follows:

$$
\begin{aligned}
& U=1.2 D+1.6 L ; \\
& U=1.2 D+1.0 L \pm 1.0 E ; \\
& U=0.9 D+1.0 E .
\end{aligned}
$$

Uniform dead and live loads of $D L=22.3 \mathrm{KN} / \mathrm{m}$ and $L L=10.7 \mathrm{KN} / \mathrm{m}$ are applied, respectively. The compressive strength of concrete is assumed to be $f_{c}^{\prime}=280 \mathrm{~kg} / \mathrm{cm}^{2}$ and the yield strength of steel is considered as $f_{y}=4200 \mathrm{~kg} / \mathrm{cm}^{2}$. The termination criteria for the algorithm can be the convergence or the number of iterations. Based on some evaluations implemented for this algorithm the number of iterations is applied as the termination criteria. To find the best population number and the best number of iterations different populations with different iterations are examined and ultimately a population of 100 members and number of repetitions of 100 obtained to be effective.

\subsection{First model}

Topology and loadings for this model, which is a representative of low rise buildings, is illustrated in Figure 2. Columns and beams are grouped into two different types. The costs for unit volume $\left(\mathrm{m}^{3}\right)$ of concrete of 30 USD, unit weight $(\mathrm{kg})$ of steel of 0.50 USD and unit area $\left(\mathrm{m}^{2}\right)$ of formwork of 4.42 USD are considered for cost estimation.

In Figures 3 and 4, the population diversity in the first iteration and the Pareto-front are shown. To obtain reliable results, ten runs are implemented and finally the best ones are shown in the figures.

Cross-sections for columns and beams are employed from $30 \times 30\left(\mathrm{~cm}^{2}\right)$ as the smallest section to $70 \times 70\left(\mathrm{~cm}^{2}\right)$ as the largest section. To determine the efficiency of the algorithm the stress ratios for structural elements are captured. Since in this model two groups for beams and two groups for columns are defined to be representative for twelve members, the average maximum stress in these groups of beams and columns are shown in Figures 5 and 6. These stress ratios are shown for the optimal solutions of the $1^{\text {st }}$, $20^{\text {th }}, 50^{\text {th }}$, and $100^{\text {th }}$ populations as representative of all members.

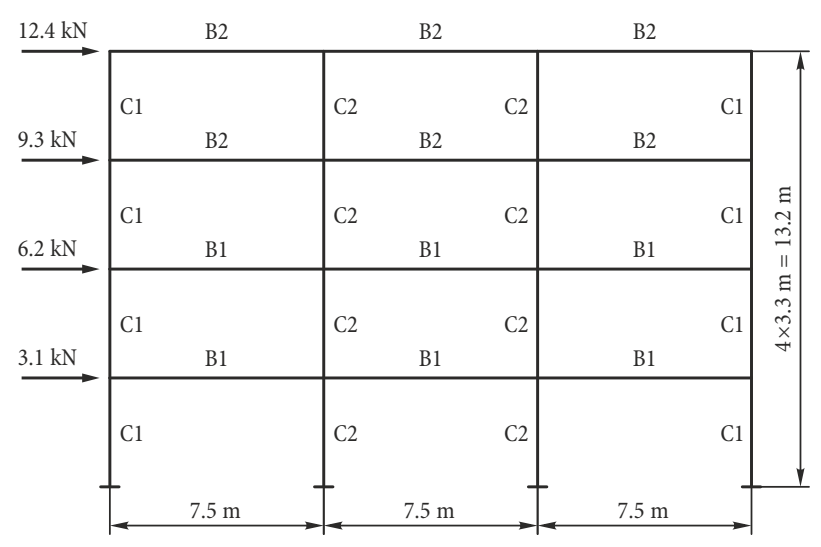

Fig. 2. Topology of the first model



Fig. 3. The population diversity in the first model



Fig. 4. Pareto-front obtained in the first model 
In Figures 7 and 8 the population number of the first front and congestion distance are illustrated. As it is clear in these figures, when the population size in the first front was increased during the iterations the algorithm decreased the congestion distance. In other

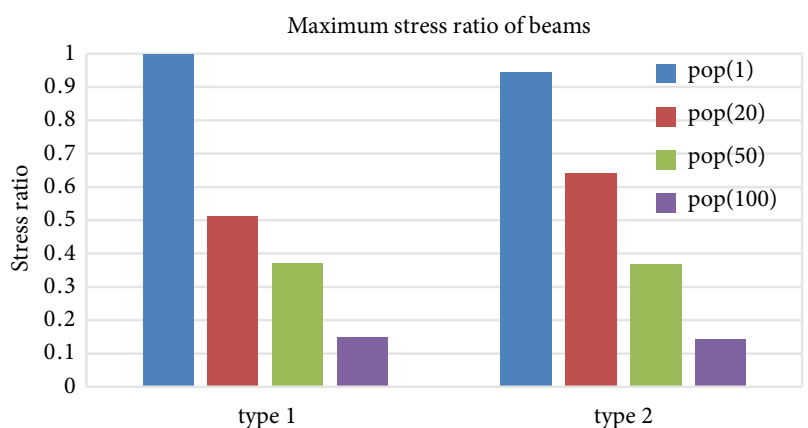

Fig. 5. Stress ratio of the first model beams groups

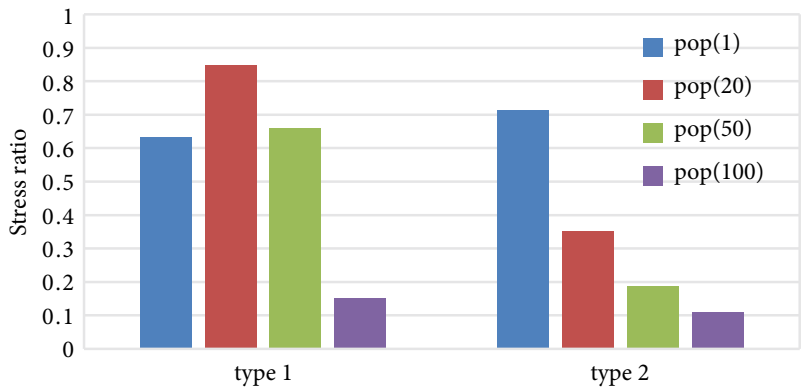

Fig. 6. Stress ratio of the first model columns groups

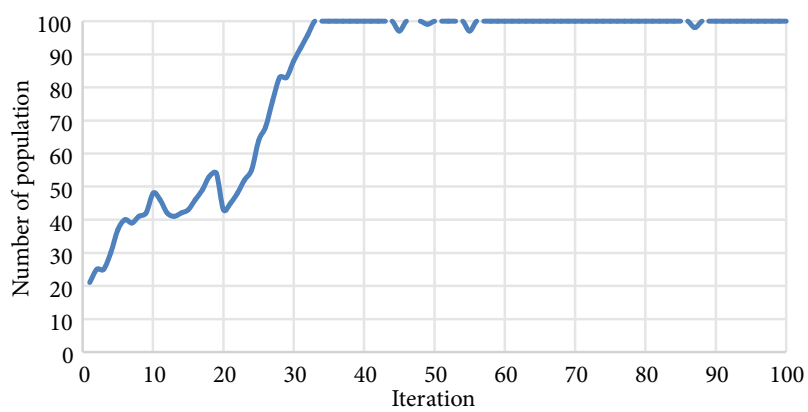

Fig. 7. The population number in the first front for the first model

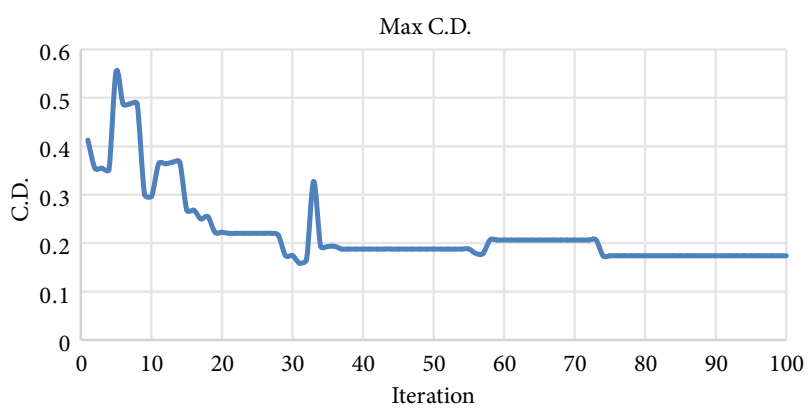

Fig. 8. Maximum values of the congestion distance in the first model (C.D.: congestion distance) words, the population diversity in the first front was improved through the iterations. As shown in Figure 7, after about 32 iterations all of the population members are selected to be a member of the first front. In other words, the algorithm distributes the solutions through the objective space in an efficient way so that no solution is dominated by another one. It should be noted that the congestion distance (C.D.) in Figure 8 is a factor to define density estimation of the solution for any specific Pareto front. It is defined as the distance of two neighbouring solutions on either side of a solution along each objective axis.

\subsection{Second model}

As with the first example, a span of $7.5 \mathrm{~m}$ and a height of $3.3 \mathrm{~m}$ are considered for this example also. Beams are grouped into three types and columns are grouped into four types as illustrated in Figure 9. Gravity loads include live loads and dead loads, same as the previous example. Grouping and loadings assumed for this sample are shown in Figure 9.

By examining the initial population in the first iteration and the obtained Pareto front from the $100^{\text {th }}$ iteration (Fig. 10), robustness of the algorithm for multi-objective optimization is clear. Considering this figure and results for the population diversity, the

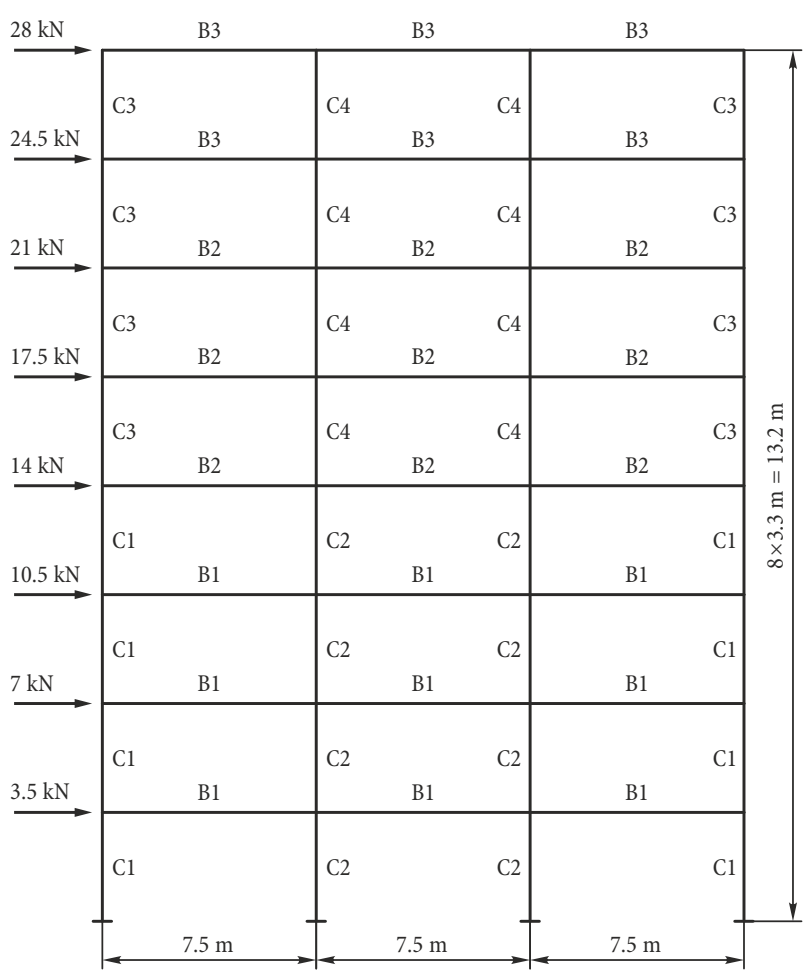

Fig. 9. Topology of the second model 
cost in the initial population varies from 7000 USD to 37000 USD, while in the final population it varies from 7000 USD to 18000 USD. The maximum roof displacement in the first population is about $30 \mathrm{~cm}$, while it is obtained $6 \mathrm{~cm}$ in the final population, which shows a sharp decrease.

In this model, to compare the stress ratio of beams and columns, four optimal solutions of the $1^{\text {st }}$, $10^{\text {th }}, 30^{\text {th }}$, and $100^{\text {th }}$ from the Pareto-front are selected, as shown in Figures 11 and 12. As expected the maximum amount of stress ratio is obtained for the first solution (with the lowest cost), while the minimum stress ratio is obtained for the $100^{\text {th }}$ solution (with the lowest displacement).

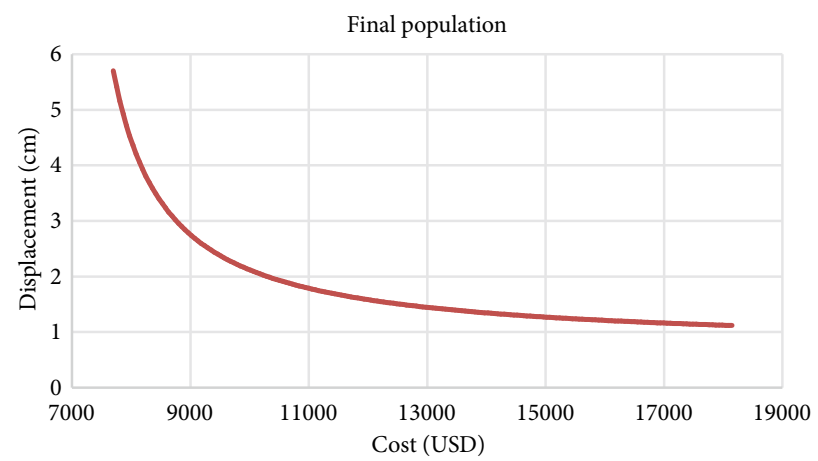

Fig. 10. Pareto-front of the second model

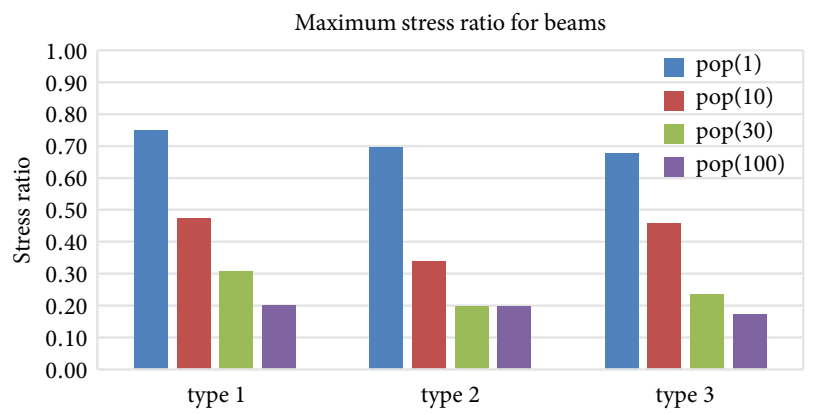

Fig. 11. The maximum stress ratio of beams for the second model

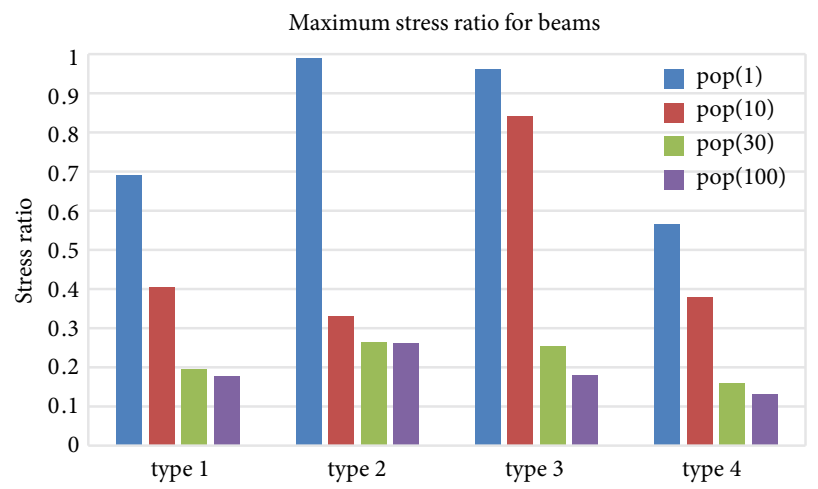

Fig. 12. The maximum stress ratio of columns for the second model

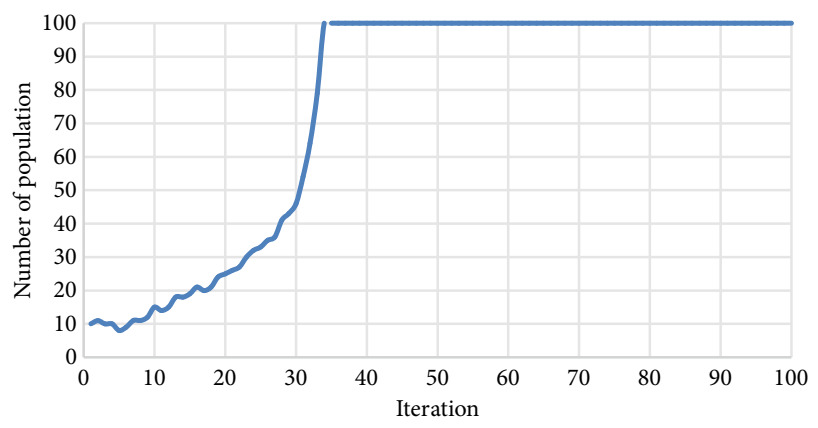

Fig. 13. The population number in the first front of the second model

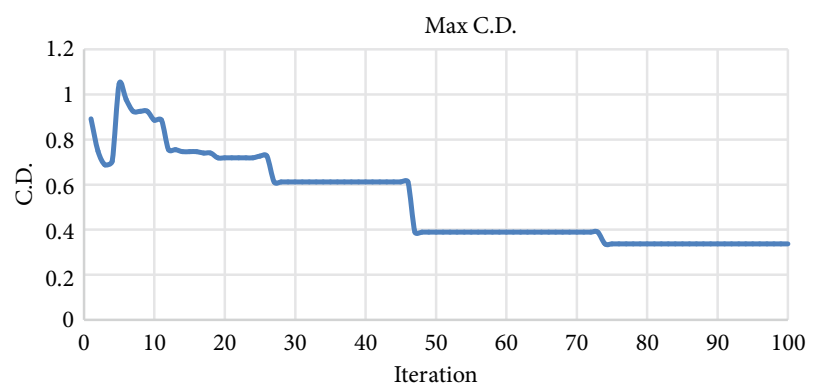

Fig. 14. Maximum values of the congestion distance in the second model

For this model, population number in the first front and the congestion distance are calculated and presented in Figures 13 and 14. It is observed that after 34 iterations all members of the population were in the first front. In other words, the algorithm distributes the solutions efficiently through the objective space. The maximum congestion distance has declined in two phases, which reflects the strength of the algorithm in sorting members in a front.

\subsection{Third model}

This example is considered to represent a tall structure. Similar span lengths and story height are considered as assumed for the previous examples. The only differences are the number of stories and the lateral loads, as shown in Figure 15. Trade-off between two objective functions, cost and maximum roof displacement, is demonstrated in Figure 16. Figures 17 and 18 illustrate the stress ration of beams and columns for four optimal solutions selected from the final Pareto-front. These four optimal solutions are representatives of the scenarios in Pareto-front showing from the upper to the lower limit of the objective functions. The population number in the first front and the congestion distance are calculated and presented in Figures 19 and 20. It is observed that after 34 iterations all members of the population were in the first front and similar to the previous examples the algorithm works efficiently. 




Fig. 15. Grouping of beams and columns in the third model

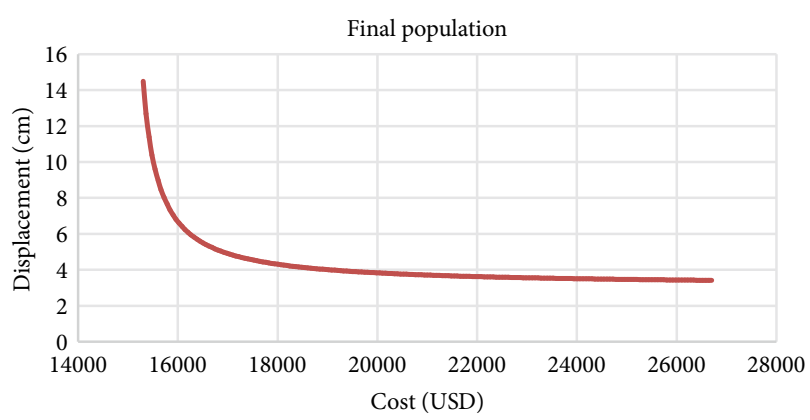

Fig. 16. Pareto-front for the third model

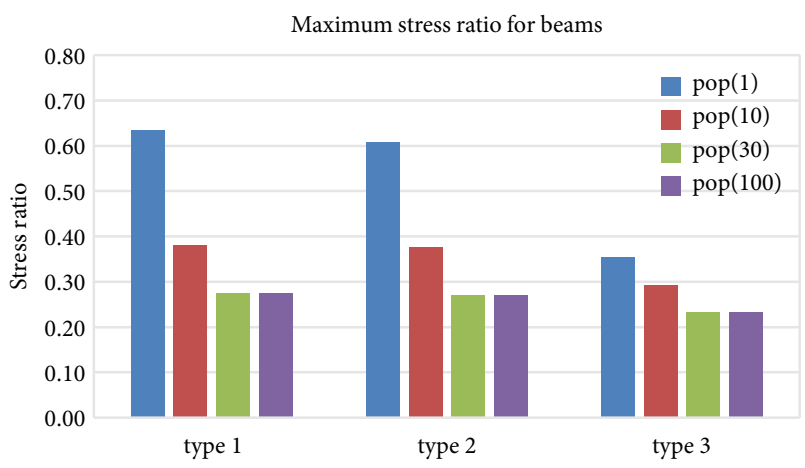

Fig. 17. The stress ratio of beams for the third model

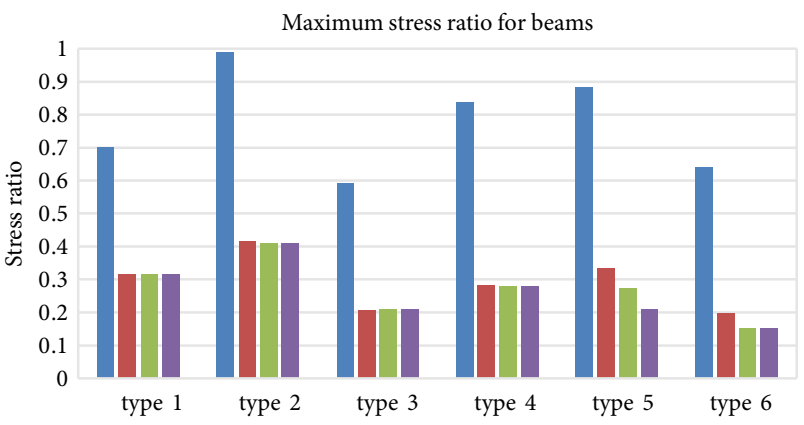

Fig. 18. The stress ratio of columns for the third model

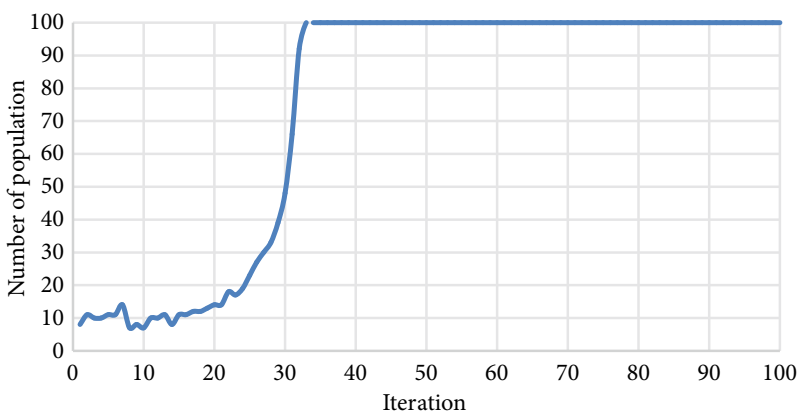

Fig. 19. The population number in the first front for the third model

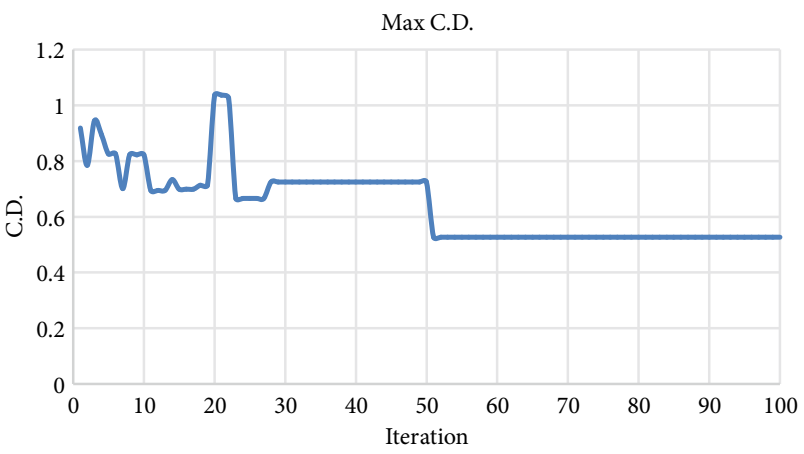

Fig. 20. Maximum values of the congestion distance in the third model

\section{Conclusions}

In this paper, a bi-objective algorithm of optimization of RC moment resisting frame has been investigated using the NSGA-II method. Two objective functions, including the total structural cost and the maximum roof displacement, which are in conflict, are defined and applied for the bi-objective optimization of RC models. Discrete variables including dimensions of sections of beams and columns were employed as design variables. Three models were considered for representative for four, eight and twelve-story buildings. Stress ratio for beams and columns, amount of congestion distance in the first front, and changing strategy for the size of the first front were presented. Trade-offs between cost and displacement objective functions 
showed potential optimal solutions, however, as shown in the article body, focusing more on displacement optimization leads to sensitive design for cost function. In other words, the trade-off curve is stretched along the cost function more than the displacement function, indicating that the most cost-effective structure does not have a very large displacement but the most stiffed structure, with the lowest displacement, needs very large sections, which leads to an expensive design. Results showed smooth Pareto-front curve for all models, which means that the algorithm is robust enough to find dominant solutions with a reasonable diversity.

\section{References}

Adamu, A.; Karihaloo, B. L.; Rozvany, G. I. N. 1994. Minimum cost design of reinforced concrete beams using continuumtype optimality, Structural and Multidisciplinary Optimization 7: 91-102. https://doi.org/10.1007/BF01742512

Andersson, J. 2001. Multiobjective optimization in engineering design: Dissertations No. 675. Linköping University.

Babaei, M. 2015a. Exploring practical optimal topology for reinforced concrete moment resisting frame structures, American Journal of Civil Engineering 3: 102-106. https://doi.org/10.11648/j.ajce.20150304.12

Babaei, M. 2015b. The economical effect of ductility levels on reinforced concrete frames design, American Journal of Civil and Structural Engineering 2: 1-6.

Babaei, M.; Jabbar, M. 2016. Optimal intermediate steel moment resisting frames with different spans and story numbers, Journal of Engineering and Applied Sciences 10(8): 223-226.

Babaei, M.; Omidi, F. 2015. Determining the optimum spans for special steel moment resisting frames with special eccentric braces, Research Journal of Applied Sciences 10(9): 474-478.

Baling, R. J.; Yao, X. 1997. Optimization of Reinforced Concrete Frames, Journal of Structural Engineering 123: 193-202. https://doi.org/10.1061/(ASCE)0733-9445(1997)123:2(193)

Camp, C. V.; Pezeshk, S.; Hansson, H. 2003. Flexural design of reinforced concrete frames using a genetic algorithm, Journal of Structural Engineering 129: 105-115.

https://doi.org/10.1061/(ASCE)0733-9445(2003)129:1(105)

Carrillo, V. M.; Taboada, H. 2012. A post-Pareto approach for multi-objective decision making using a non-uniform weight generator method, Procedia Computer Science 12: 116-121. https://doi.org/10.1016/j.procs.2012.09.040

Deb, K. 2001. Multi-objective optimization using evolutionary algorithms. John-Wiley \& Sons.
Deb, K.; Agrawal, S.; Pratap, A.; Meyarivan, T. 2000. A fast elitist non-dominated sorting genetic algorithm for multiobjective optimization: NSGA-II, Lecture Notes in Computer Science 1917: 849-858.

https://doi.org/10.1007/3-540-45356-3_83

Gervyte, A.; Jarmolajeva, E. 2013. Analysis and optimization of elastic-plastic framing structures under complex constraints, Engineering Structures and Technologies 5(4): 159-166. https://doi.org/10.3846/2029882X.2014.898366

Ghosh, A; Dehuri, S. 2004. Evolutionary algorithms for multicriterion optimization: a survey, International Journal of Computing \& Information Sciences 2(1): 38-57.

Hoit, M.; Soeiro, A.; Fagunda, F. 1991. Probabilistic design and optimization of reinforced concrete frames, Journal of Engineering Optimization 17: 229-235.

Horn, J.; Nafpliotis, N.; Goldberg, D. E. (Eds.). 1994. A niched Pareto genetic algorithm for multi-objective optimization, in Proceedings of the First IEEE Conference on Evolutionary Computation, IEEE World Congress on Computational Intelligence, 27-29 June 1994, Orlando, Florida, 1: 82-87.

Kaveh, A.; Sabzi, O. 2011. A Comparative study of two metaheuristic algorithms for optimum design of reinforce concrete frames, International Journal of Civil Engineering 9(3): 193-206.

Kaveh, A.; Sabzi, O. 2012. Optimal design of reinforced concrete frames using big bang big crunch algorithm, International Journal of Civil Engineering 10(3): 189-200.

Kim, I.Y.; De Weck, O. 2005. Adaptive weighted-sum method for bi-objective optimization: Pareto front generation, Structural and Multidisciplinary Optimization 29(2): 149-158. https://doi.org/10.1007/s00158-004-0465-1

Park, H. S.; Kwon, B.; Shin, Y.; Kim, Y.; Hong, T.; Choi, S.W. 2013. Cost and $\mathrm{CO}_{2}$ emission optimization of steel reinforced concrete columns in high-rise buildings, Energies 11: 5609-5624. https://doi.org/10.3390/en6115609

Park, J. H.; Jeon, J. H.; Park, H. S. 2012. Optimization of CO${ }_{2}$ emissions and cost for composite building design with NSGAII, Creative Research Support Project (No. 2011-0018360).

Sanaei, E.; Babaei, M. 2012. Topology Optimization of structures using cellular automata with constant strain triangles, International Journal of Civil Engineering 10(3): 179-188.

Sarker, R; Liang, K.-H.; Newton, C. 2002. A new multiobjective evolutionary algorithm, European Journal of Operational Research 140(1): 12-23. https://doi.org/10.1016/S0377-2217(01)00190-4

Stanković, T.; Štorga, M.; Marjanović, D. 2012. Synthesis of truss structure designs by NSGA-II and NodeSort algorithm, Strojniški vestnik - Journal of Mechanical Engineering 58(3):203-212. https://doi.org/10.5545/sv-jme.2011.042

Mehdi BABAEI is an Assistant Professor in the Department of Civil Engineering at the University of Zanjan. He received his PhD (2012) and Master's (2003) degrees in Structural Engineering from the Iran University of Science and Technology after obtaining his Bachelor's in Civil Engineering in 2000. During his PhD study, he visited the Oxford University as a research student as well as participated in a short program at the Massachusetts Institute of Technology in 2010. His research has focused on the optimal design of structures, tall buildings, spatial structures, structural systems and sustainable design.

Masoud MOLLAYI earned his MSc in Structural Engineering from the University of Zanjan in 2015, after receiving his Bachelor in Civil Engineering. His main interest is to study heuristic algorithms and to develop new algorithms for structural optimization. 